\title{
Distinct tumour antigen-specific T-cell immune response profiles at different hepatocellular carcinoma stages
}

Chaoran Zang ${ }^{1,2}$, Yan Zhao ${ }^{3}$, Ling Qin ${ }^{1}$, Guihai Liu ${ }^{1,4,5}$, Jianping Sun ${ }^{1}$, Kang Li $i^{1}$, Yanan Zhao ${ }^{6}$, Shoupeng Sheng ${ }^{2}$, Honghai Zhang ${ }^{2}$, Ning He ${ }^{2}$, Peng Zhao ${ }^{2}$, Qi Wang ${ }^{1,2}, X_{i} \mathrm{Li}^{4,5}$, Yanchun Peng ${ }^{4,5}$, Tao Dong ${ }^{4,5^{*}}$ and Yonghong Zhang ${ }^{1,2^{*}}$

\begin{abstract}
Background: Cancer-testis antigens (CTAs) and tumour-associated antigens (TAAs) are frequently expressed in hepatocellular carcinoma (HCC); however, the role of tumour-antigen-specific T cell immunity in HCC progression is poorly defined. We characterized CTA- and TAA-specific T cell responses in different HCC stages and investigated their alterations during HCC progression.

Methods: Fifty-eight HCC patients, 15 liver cirrhosis patients, 15 chronic hepatitis B patients and 10 heathy controls were enrolled in total. IFN- $\gamma$ ELSPOT using CTAs, including MAGE-A1, MAGE-A3, NY-ESO-1, and SSX2, and two TAAs, SALL4 and AFP, was performed to characterize the T-cell immune response in the enrolled individuals. The functional phenotype of T cells and the responsive T cell populations were analyzed using short-term T-cell culture.

Results: T cell responses against CTAs and TAAs were specific to HCC. In early-stage HCC patients, the SALL4specific response was the strongest, followed by MAGE-A3, NY-ESO-1, MAGE-A1 and SSX2. One-year recurrence-free survival after transcatheter arterial chemoembolization plus radiofrequency ablation treatment suggested the protective role of CTA-specific responses. The four CTA- and SALL4-specific T cell responses decreased with the progression of HCC, while the AFP-specific T cell response increased. A higher proportion of CD4+ T cells specific to CTA/SALL4 was observed than AFP-specific T cell responses.

Conclusions: The IFN- $\gamma$ ELISPOT assay characterized distinct profiles of tumour-antigen-specific $T$ cell responses in HCC patients. CTA- and SALL4-specific T cell responses may be important for controlling HCC in the early stage, whereas AFP-specific T cell responses might be a signature of malignant tumour status in the advanced stage. The application of immunotherapy at an early stage of HCC development should be considered.
\end{abstract}

Keywords: Cancer-testis antigen, Distinction, Hepatocellular carcinoma, T cell immune response, Tumour-associated antigen

\footnotetext{
* Correspondence: tao.dong@imm.ox.ac.uk; zhangyh@ccmu.edu.cn

${ }^{4} \mathrm{MRC}$ Human Immunology Unit, MRC Weatherall Institute of Molecular Medicine, Oxford University, Oxford, UK

${ }^{1}$ Biomedical Information Center, Beijing YouAn Hospital, Capital Medical University, Beijing, China

Full list of author information is available at the end of the article
}

(c) The Author(s). 2021 Open Access This article is licensed under a Creative Commons Attribution 4.0 International License, which permits use, sharing, adaptation, distribution and reproduction in any medium or format, as long as you give appropriate credit to the original author(s) and the source, provide a link to the Creative Commons licence, and indicate if changes were made. The images or other third party material in this article are included in the article's Creative Commons licence, unless indicated otherwise in a credit line to the material. If material is not included in the article's Creative Commons licence and your intended use is not permitted by statutory regulation or exceeds the permitted use, you will need to obtain permission directly from the copyright holder. To view a copy of this licence, visit http://creativecommons.org/licenses/by/4.0/ The Creative Commons Public Domain Dedication waiver (http://creativecommons.org/publicdomain/zero/1.0/) applies to the data made available in this article, unless otherwise stated in a credit line to the data. 


\section{Introduction}

Hepatocellular carcinoma (HCC) is the fourth most common cause of cancer-related death and ranks sixth in incidence worldwide [1]. The incidence of HCC is particularly serious in China, and over $50 \%$ of global newly diagnosed liver cancer cases and liver cancerrelated deaths occur in China [2]. Therefore, there is an urgent need for effective HCC therapies, including those targeting antigens expressed by $\mathrm{HCC}$ as a result of tumour occurrence.

Host immunosurveillance, which plays an important role in tumorigenesis by eliminating tumour cells and suppressing tumour growth, was proposed by Paul Ehrlich a century ago [3, 4]. Several studies have shown that the immune system plays an important role in the occurrence and development of $\operatorname{HCC}[5,6]$. The function of the immune system changes during the development of HCC. Cytotoxic T lymphocytes, which target HCC tumour cells, are especially important regulators of tumour progression and protect $\mathrm{HCC}$ patients $[7,8]$. Recently, immune checkpoint inhibitor-based immunotherapy for $\operatorname{HCC}[9,10]$ has not only provided additional evidence supporting the role of the immune system in controlling $\mathrm{HCC}$ progression but also revealed that our understanding of the $\mathrm{T}$ cell immune response to $\mathrm{HCC}$ is insufficient, especially in terms of diverse $\mathrm{T}$ cell immunity in different stages of HCC.

The tumour antigens recognized by $\mathrm{T}$ cells have not been well characterized and may be immunogenic neoantigens that have not yet been identified in HCC. However, several cancer testis antigens (CTAs) whose expression is limited to cancer cells and reproductive tissues and is not found in adult somatic tissue can spontaneously induce a $\mathrm{T}$ cell response in $\mathrm{HCC}$ patients. CTAs comprise a range of self-derived proteins, such as melanoma-associated antigen A1 (MAGE-A1), MAGEA3, New York esophageal squamous cell carcinoma antigen 1 (NY-ESO-1), and synovial sarcoma $\mathrm{X}$ break point gene 2 (SSX2), that can become immunogenic in HCC either by mutation or aberrant expression. These are currently popular and widely investigated CTAs in the field of HCC; however, the data on their involvement in HCC are insufficient [11-13]. In addition to CTAs, tumour-associated antigens (TAA) are also enriched (but not specific) in cancer cells [14]. Sal-like protein 4 (SALL4) is a type of TAA; although SALL4 is not expressed in the majority of normal human tissues, it is expressed in human embryonic stem cells, testes and ovaries, is highly expressed in HCC and is associated with aggressive HCC [15]. Alpha-fetoprotein (AFP) is derived from embryonic endoderm tissue cells. The content of AFP is high during foetal development and gradually decreases to the level observed in adults after birth. The majority of HCC patients have high levels of this antigen. Other malignant tumours of the stomach and pancreas are also often accompanied by a small number of increased AFPs [16]. Targeting CTA and/or TAA using vaccination strategies has been suggested because of their frequent expression in a large proportion of HCC cells (i.e.: MAGE-A1 and A3: > 50\%; NY-ESO-1 > $30 \%$, and SSX2 > 70\%) $[11,17,18]$.

Very few researchers have performed detailed and combined analyses of important tumour antigen-specific $\mathrm{T}$ cell responses and their associations with different HCC statuses. To address this issue, 98 individuals, including healthy controls (HCs) and those with different stages of HCC, liver cirrhosis (LC), or chronic hepatitis $B$ virus infection (CHB), were enrolled. Overlapping peptides were synthesized to perform comprehensive $\mathrm{T}$ cell response analysis, covering CTAs (MAGE-A1, MAGEA3, NY-ESO-1, SSX2) and TAAs (SALL4 and AFP). The goal of this study was to further clarify the diverse characteristics of tumour antigen-specific $\mathrm{T}$ cells among different HCCs.

\section{Patients and methods \\ Patients and samples}

In total, 98 individuals from Beijing YouAn Hospital were recruited, including $58 \mathrm{HCC}, 15 \mathrm{LC}, 15 \mathrm{CHB}$, and $10 \mathrm{HC}$ individuals. The inclusion criteria were as follows: 1) diagnosis of HCC; 2) age between 18 and 75 years; and 3) patients who were unsuitable for or unwilling to receive surgery and were assessed as able to tolerate transcatheter arterial chemoembolization (TACE) or/and radiofrequency ablation (RFA) as a palliative or curative therapy. The exclusion criteria were as follows: 1) other malignancies; 2) severe coagulation disorders; 3) secondary liver cancer; 4) other immune-related diseases; and 5) any immunotherapy. The diagnostic criteria of HCC were applied according to the European Association for the Study of the Liver-European Organization for Research and Treatment of Cancer Clinical Practice Guidelines: Management of Hepatocellular Carcinoma [19], and HCC was classified based on the Barcelona Clinic Liver Cancer (BCLC) staging system [20]. At our interventional therapy centre, TACE combined with ablation therapy is the best option among the available interventional treatment strategies and is more effective than TACE or ablation treatment alone [21, 22]. We have performed many studies, and this strategy has become the standard therapy applied by our team [23-26]. Forty-one of the $58 \mathrm{HCC}$ patients who were evaluated as suitable for TACE combined with RFA therapy received curative treatments and were followed up with every 3 months for 1 year. All $41 \mathrm{HCC}$ patients underwent dynamic contrast enhancement $\mathrm{CT}$ scans to evaluate recurrence [27]. In addition, the diagnosis of $\mathrm{LC}$ and $\mathrm{CHB}$ was made according to previously reported guidelines 
$[28,29]$. The study, conforming to the tenets of the 1990 Declaration of Helsinki, was approved by the Institutional Review Board of Beijing YouAn Hospital. Written informed consent was obtained from all candidates. Ten millilitres of blood from each patient was collected, and PBMCs were isolated by density gradient centrifugation.

\section{Synthetic peptides for T-cell analysis}

A total of 334 overlapping peptides (18-mers overlapping by 10 amino acids) spanning the complete amino acid sequence of SALL4, MAGE-A1, MAGE-A3, NYESO-1, SSX2 and AFP were utilized. Their purities were determined to be $>90 \%$ by analytical high-performance liquid chromatography. Peptides were dissolved in dimethylsulfoxide (Sigma, Haverhill, Suffolk, UK) and diluted with RPMI 1640 before being combined into nine pools with $23-45$ peptides per pool (Table S1).

\section{Human IFN- $\gamma$ ELISPOT assay}

As described previously [30], a total of 250,000 PBMCs with $8 \mu \mathrm{g} / \mathrm{mL}$ peptide per well containing RPMI 1640 medium with 10\% FCS were used in a standard human IFN- $\gamma$ ELISPOT assay. In brief, assays were carried out in 96-well MultiScreen filter plates (Millipore) coated with $15 \mathrm{mg} / \mathrm{mL}$ anti-IFN- $\gamma \mathrm{mAb}$ (1-DIK; Mabtech). Phytohaemagglutinin $(10 \mu \mathrm{g} / \mathrm{mL})$ was used as a positive control. Plates were incubated for $16-18 \mathrm{~h}$. The plate was washed 5 times, and biotin-conjugated anti-human IFN- $\gamma$ Ab (Mabtech, Nacka, Sweden) was added and reacted for $2 \mathrm{~h}$. After washing the plate 5 times, streptavidin-ALP (Mabtech, Nacka, Sweden) was added and reacted for $1 \mathrm{~h}$. Finally, newly prepared NBT/BCIP solution (Bio-Rad, Hercules, CA) was added for colour development after washing. The reaction was stopped by washing with distilled water, and the plate was dried at room temperature. Spot enumeration was performed with a CTL ELISPOT reader system (Cellular Technology Ltd., S6 Universal, America). To quantify antigenspecific responses, mean spots of the negative control were subtracted from the reaction wells, and the results were expressed as spot-forming units (SFUs) per $10^{6}$ PBMCs. Responses were regarded as positive if the results were at least three times the mean of the negative control wells and above 25 SFUs $/ 10^{6}$ PBMCs. If background wells were $25 \mathrm{SFUs} / 10^{6} \mathrm{PBMCs}$ or positive control wells were negative, the results were excluded from further analysis.

\section{Generation of tumour antigen specific T-cell lines}

According to the IFN- $\gamma$ ELISPOT results and the remaining samples, PBMCs from 5 HCC subjects were stimulated with the corresponding responsive antigen. Overlapping peptides were added to 200,000 cells for stimulation for $1 \mathrm{~h}$ and then the cells were grown in 96- well plates. Short-term $T$ cell lines were grown for 10 days in $\mathrm{AIM}-\mathrm{V}+10 \%$ human $\mathrm{AB}$ serum (Invitrogen, Carlsbad, CA) supplemented with $100 \mu \mathrm{g} / \mathrm{mL}$ (final concentration) interleukin (IL)-2 (R\&D Systems, Minneapolis, MN). In total, 19 antigen-specific $\mathrm{T}$ cell lines were generated.

\section{Intracellular cytokine staining}

For intracellular cytokine staining, PBMCs were stimulated with the corresponding pooled peptide at a final concentration of $8 \mu \mathrm{g} / \mathrm{mL}$ for $1 \mathrm{~h}$ at $37^{\circ} \mathrm{C}$. Then, the cells were incubated for an additional $4 \mathrm{~h}$ with $1 \mu \mathrm{g} / \mathrm{mL}$ GolgiPlug (Brefeldin A, BD) and $0.7 \mu \mathrm{g} / \mathrm{mL}$ GolgiStop (Monensin, BD) and surface stained with CD107a-PE-CF594 (BD Bioscience). Unstimulated cells were used as negative controls. A combination of $50 \mathrm{ng} / \mathrm{mL}$ phorbol-12-myristate13-acetate and $1 \mu \mathrm{g} / \mathrm{mL}$ ionomycin (both Sigma-Aldrich, Seelze, Germany) was used as a positive control. Dead cells were stained with LIVE/DEADR Fixable Aqua dye (Invitrogen). Surface markers, including CD3-AF700 (BioLegend), CD4-FITC (BD Bioscience), and CD8-APC-H7 (BD Bioscience), were stained. Cells were then washed and permeabilized using Cytofix/Cytoperm (BD Bioscience). Subsequently, the cells were washed with Perm/ Wash buffer (BD Bioscience), stained intracellularly with Tumour Necrosis Factor (TNF)- $\alpha$-APC (BioLegend), IFN$\gamma$-BV786 (BD Bioscience), and IL-2-PE (BioLegend), fixed with $1 \times$ CellFix solution (BD Biosciences) and acquired immediately on a BD LSR Fortessa. The data were analysed using FlowJo (Tree Star Inc., Ashland OR).

\section{Statistical analysis}

Continuous variables are expressed as the mean \pm standard deviation (SD). Statistical analysis of the data was performed using the $\chi^{2}$ test for constituent ratio analysis. Two-tailed Student's t tests were used to compare parametric continuous data, and the Mann-Whitney U test was used when data were not normally distributed. Statistical significance was set at $P<0.05$. Analyses were performed with SPSS software v25 (IBM, New York, USA), and graphs were constructed with GraphPad Prism 8.0 (GraphPad software Inc).

\section{Results}

CTA and TAA-specific T cell responses were detected in HCC patients

A total of 98 individuals were enrolled in the study: 58 had HCC, 15 had LC, 15 had CHB, and the remaining 10 were HCs. All HCC patients were classified according to the BCLC staging system. The tumour burden was significantly different among patients with different stages of HCC. Patients with early-stage (BCLC-0/A) $\mathrm{HCC}$ were more likely than patients with advanced-stage (BCLC-B/C) HCC to have solitary tumour lesions (84\% 
vs. $39.39 \%, P=0.001)$, small tumour volumes $(76 \%$ vs. $30.3 \%, P=0.001)$, and no vascular invasion $/$ metastasis (100\% vs. $54.55 \%, P<0.0001)$. AFP and protein induced by vitamin $\mathrm{K}$ absence or antagonist-II (PIVKA-II), two HCC biomarkers, were analysed, and the PIVKA-II value of early-stage patients was lower than that in advancedstage patients $[84.50(23.00,374.25) \mathrm{mAU} / \mathrm{mL}$ vs. 512 (60.50, 4051.50) mAU/mL, $P=0.005$ ] (Table 1).

CTA- and TAA-specific $\mathrm{T}$ cell responses were detected by IFN- $\gamma$ ELISPOT assays in all 98 individuals to evaluate the comprehensive $\mathrm{T}$ cell response and its specificity. In total, $67.24 \%(39 / 58)$ of HCC patients responded to at least one $\mathrm{CTA}$ or TAA. In contrast, no positive response was found in any individual in any control group (LC, CHB, and $\mathrm{HC}$ ) (Fig. S1). The difference between $\mathrm{HCC}$ and all control individuals was significant $(P<0.0001)$ (Fig. 1$)$. Among the $58 \mathrm{HCC}$ patients studied, $37.93 \%(22 / 58)$ responded to SALL4, $32.76 \%(19 / 58)$ to MAGE-A3, 23.40\% (11/47) to MAGEA1, $10.64 \%(5 / 47)$ to NY-ESO-1, $10.64 \%(5 / 47)$ to SSX2, and $37.93 \%(22 / 58)$ to AFP.
Distinct profiles of CTA- and TAA-specific T cell responses in patients with different HCC clinical characteristics The analysis of the distribution of $\mathrm{T}$ cell responses revealed distinct patterns of CTA- and TAA-specific $\mathrm{T}$ cell responses among patients with different stages of HCC. Among patients with early-stage HCC, the strongest response was against SALL4 (66.88 \pm 22.23 SFUs $/ 10^{6}$ cells), followed by MAGE-A3 (32.16 \pm 14.95 SFUs $/ 10^{6}$ cells $), \quad$ NY-ESO-1 $\left(22.21 \pm 10.32\right.$ SFUs $/ 10^{6}$ cells), MAGE-A1(18.21 \pm 6.79 SFUs $/ 10^{6}$ cells $)$ and SSX2 $\left(12.84 \pm 6.38\right.$ SFUs $/ 10^{6}$ cells $)$, while the AFPspecific $\mathrm{T}$ cell response was relatively low (only $18.88 \pm 10.01$ SFUs $/ 10^{6}$ cells). The difference between the SALL4-specific and AFP-specific $\mathrm{T}$ cell responses in these patients was significant $(P=0.0173)$ (Fig. 2A). Among patients with advanced-stage disease, the AFP-specific $\mathrm{T}$ cell response was the strongest $\left(146.18 \pm 58.75\right.$ SFUs $/ 10^{6}$ cells $)$, and much higher than SALL4 $\left(19.15 \pm 10.87\right.$ SFUs $/ 10^{6}$ cells, $\left.P=0.0157\right)$, MAGE-A3 (16 \pm 5.63 SFUs $/ 10^{6}$ cells, $\left.P=0.0504\right)$, MAGE-A1 $\left(4.93 \pm 2.42\right.$ SFUs $/ 10^{6}$ cells, $\left.P=0.0015\right)$,

Table 1 Characteristics of enrolled individuals

\begin{tabular}{|c|c|c|c|c|c|}
\hline & \multicolumn{3}{|l|}{ controls } & \multicolumn{2}{|l|}{$\mathrm{HCC}$} \\
\hline & $\mathrm{HC}(n=10)$ & CHB $(n=15)$ & LC $(n=15)$ & $0+A(n=25)$ & $\mathrm{B}+\mathrm{C}(n=33)$ \\
\hline Gender (Male/Female) & $7 / 3$ & $9 / 6$ & $11 / 4$ & $19 / 6$ & $30 / 3$ \\
\hline Age & $51.39 \pm 1.49$ & $49.56 \pm 12$ & $48.33 \pm 9.11$ & $52.53 \pm 5.80$ & $51.82 \pm 11.82$ \\
\hline HBV/HCV/other & / & / & / & $21 / 3 / 1$ & $29 / 3 / 1$ \\
\hline HBV-DNA (positive/negative/ND) & / & $8 / 7 / 0$ & $5 / 10 / 0$ & $4 / 6 / 15^{b}$ & $9 / 10 / 14^{b}$ \\
\hline Tumour number (solitary/multiple) & / & / & / & $21 / 4$ & $13 / 20$ \\
\hline Tumour volume $(\mathrm{S} / \mathrm{H})^{\mathrm{c}}$ & / & / & / & $19 / 6$ & $10 / 23$ \\
\hline VI/M (no/yes) & / & / & / & $25 / 0$ & 18/15 \\
\hline Differentiation (well/moderate/poor/ND) & / & / & / & $2 / 2 / 3 / 18$ & $1 / 6 / 4 / 22$ \\
\hline Curative therapy (no/yes) & / & / & / & $3 / 22$ & $17 / 16$ \\
\hline Recurrence at 1-year (no/yes) & / & / & / & $11 / 11$ & $5 / 11$ \\
\hline WBC $\left(10^{9} / L\right)$ & $5.22 \pm 1.26$ & $6.18 \pm 2.29$ & $4.83 \pm 1.88$ & $4.34 \pm 1.63^{b}$ & $5.26 \pm 2.39$ \\
\hline $\mathrm{HGB}(\mathrm{g} / \mathrm{L})$ & $141.29 \pm 11.48$ & $147.17 \pm 21.97$ & $154.33 \pm 18.49$ & $141.42 \pm 19.39$ & $141.16 \pm 19.67$ \\
\hline $\operatorname{PLT}\left(10^{9} / \mathrm{L}\right)$ & $221.43 \pm 72.04$ & $199.17 \pm 70.41$ & $128.42 \pm 73.48^{a, b}$ & $103.88 \pm 48.64^{\mathrm{a}, \mathrm{b}}$ & $154.66 \pm 90.71$ \\
\hline ALT $(U / L)$ & N.D. & $35.13 \pm 26.50$ & $42.29 \pm 43.37$ & $32.17 \pm 23.26$ & $48.88 \pm 38.08$ \\
\hline AST (U/L) & N.D. & $41.07 \pm 47.89$ & $43 \pm 31.51$ & $36.30 \pm 17.38$ & $42.92 \pm 23.08^{b}$ \\
\hline TBiL ( $\mu \mathrm{mmol} / \mathrm{L})$ & N.D. & $16.49 \pm 6.08$ & $33.16 \pm 23^{b}$ & $21.02 \pm 12.41$ & $17.90 \pm 9.15$ \\
\hline ALB (g/L) & N.D. & $44.78 \pm 3.31$ & $42.34 \pm 5.94$ & $38.32 \pm 5.58^{b}$ & $39.82 \pm 4.91^{\mathrm{b}}$ \\
\hline $\mathrm{PT}(\mathrm{s})$ & N.D. & N.D. & $15.27 \pm 4.65$ & $13.10 \pm 1.61$ & $12.37 \pm 1.26$ \\
\hline PTA (\%) & N.D. & N.D. & $70.33 \pm 17.88$ & $80.17 \pm 13.54$ & $86.97 \pm 11.53$ \\
\hline $\operatorname{AFP}(\mathrm{ng} / \mathrm{mL})$ & / & / & / & $169.21 \pm 298.08$ & $8729.39 \pm 31,115.08$ \\
\hline PIVKA-II (mAU/mL) & / & / & / & $355.73 \pm 603.26$ & $3574.86 \pm 7725.33$ \\
\hline
\end{tabular}

Abbreviations: $\mathrm{HC}$, healthy control. CHB, chronic hepatitis B. LC, liver cirrhosis derived from CHB. HBV, hepatitis B virus; VI/M, vascular invasion/metastasis; ND, not determined. WBC, White Blood Cell. HGB, hemoglobin. PLT, platelet. ALT, alanine aminotransferase. AST, aspartate aminotransferase. TBil, total bilirubin. ALB, albumin. PT, prothrombin time. PTA, prothrombin activity. AFP, alpha-fetoprotein. PIVKA-II, protein induced by vitamin $\mathrm{K}$ absence or antagonist-II Data were expressed as mean \pm SD. ${ }^{a}: \mathrm{p}<0.05$ compared with the $\mathrm{HC}$ group. ${ }^{\mathrm{b}}: \mathrm{p}<0.05$ compared with the CHB group. ${ }^{c}:$ we divided the patients into two groups according to the tumour volume, $\mathrm{S}$ indicates tumour volume $<15 \mathrm{~cm}^{3}$ and $\mathrm{H}$ means the tumour volume $>15 \mathrm{~cm}^{3}$ 


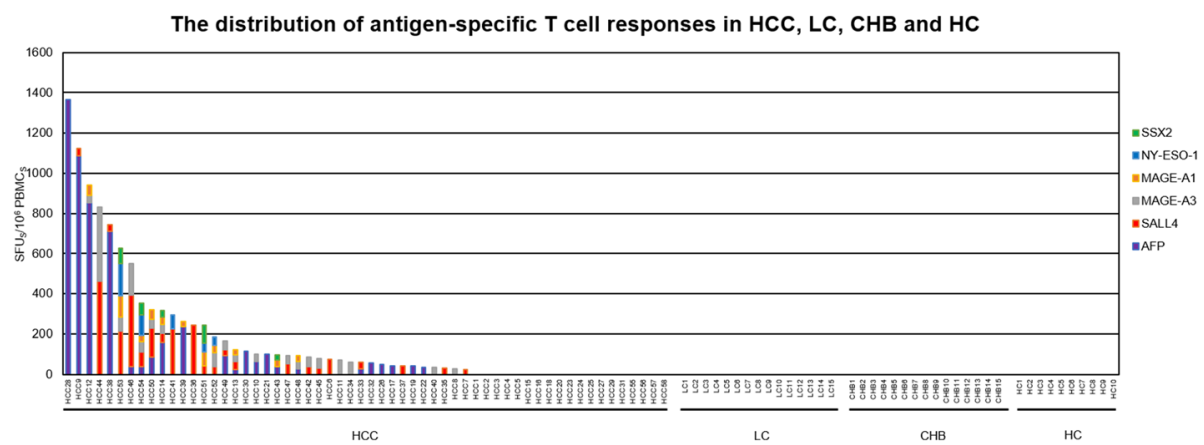

Fig. 1 The distribution of CTA and TAA-specific T cell responses in HCC, LC, CHB and HC. CTA and TAA-specific T cell responses specific to AFP (purple), SALL4 (red), MAGE-A3 (grey), MAGE-A1 (orange), NY-ESO-1 (blue) and SSX2 (green) in 58 HCC patients, 15 LC patients, 15 CHB patients and $10 \mathrm{HC}$ controls. The magnitude of T cell response was evaluated with SFU/106 PBMCs in vertical coordinates (y axis), and 98 candidates, including HCC patients, LC patients, CHB patients and Healthy Control (HC), were labelled in horizontal ordinate ( $x$ axis)

SSX2 $\left(1.21 \pm 1.22\right.$ SFUs $/ 10^{6}$ cells, $\left.P<0.0001\right)$ and NYESO-1 (0, $P<0.0001)$ responses (Fig. 2B).

Interestingly, the magnitude and frequency of CTAand SALL4-specific $\mathrm{T}$ cell responses was decreased in patients with advanced-stage HCC compared to those with early-stage $\mathrm{HCC}$, although not all differences reached statistical significance. On the other hand, the AFP-specific $\mathrm{T}$ cell response showed a trend of increasing with the progression of HCC (Fig. 2C). Further analysis of the $\mathrm{T}$ cell response profile was therefore performed comparing early and advanced stages of HCC. The results showed that the combination of a positive CTA- and SALL4-specific T cell response and a negative AFP-specific $\mathrm{T}$ cell response was present in the majority of early-stage HCC patients. In contrast, a combination of a negative CTA- and SALL4-specific T cell

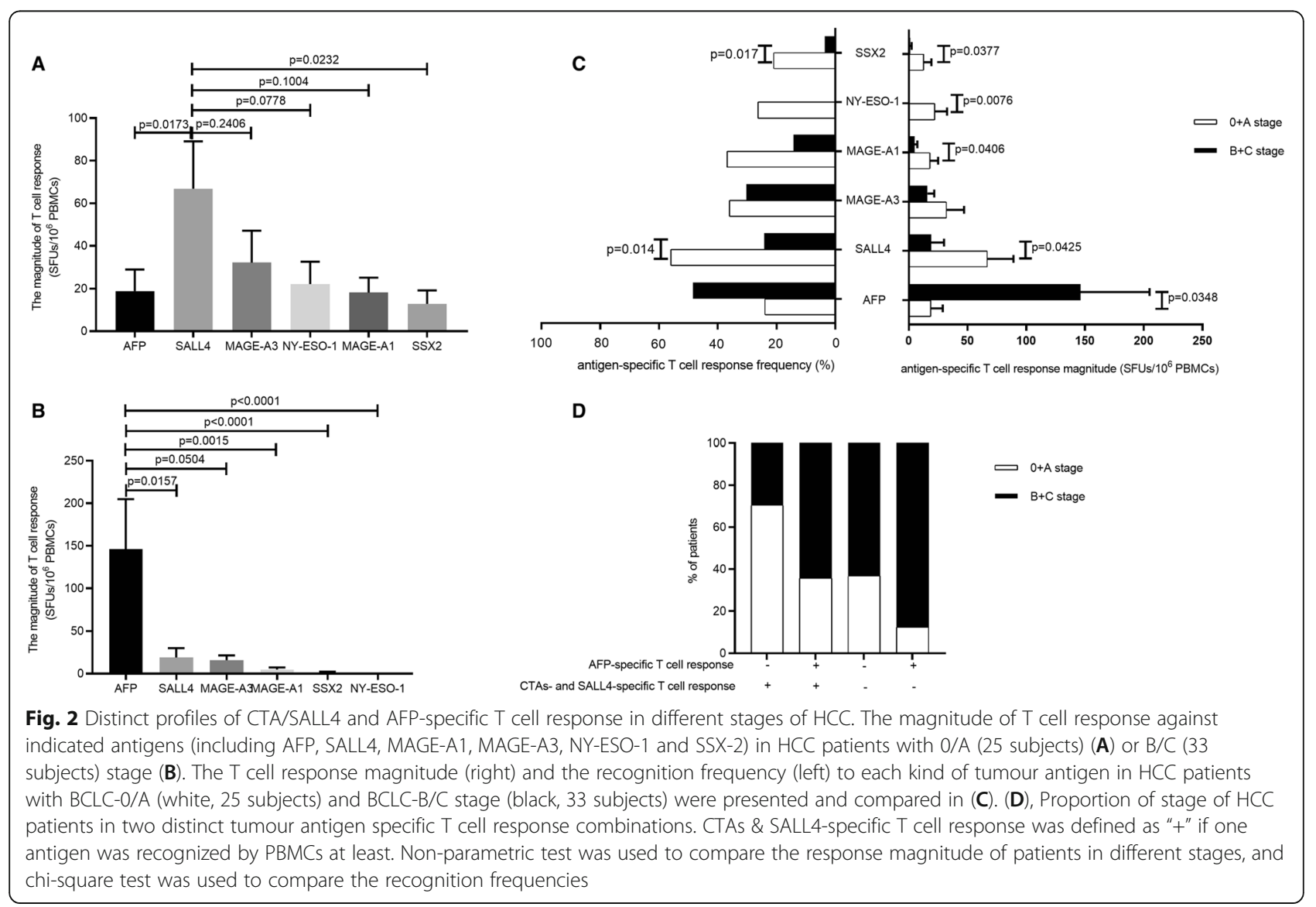



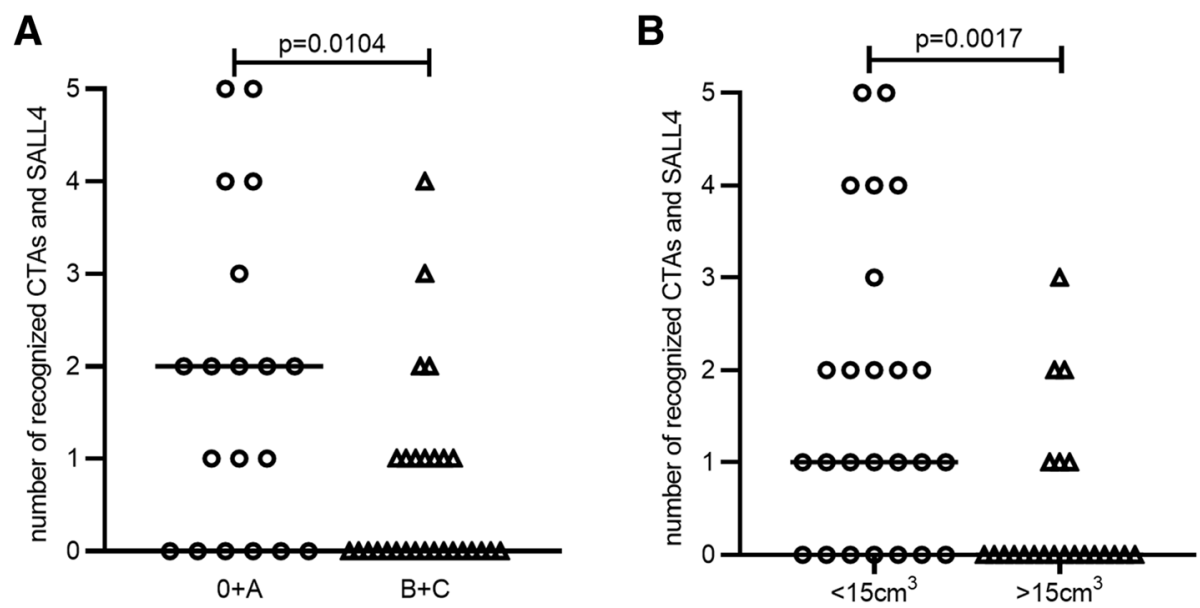

Fig. 3 Breadth of CTA/SALL4-specific T cell response. The number of recognized individual CTA \& SALL4 is shown for HCC patients according to the stage ( 25 subjects in 0/A stage and 33 subjects in B/C stage) $(\mathbf{A})$ and the tumour volume ( 25 subjects with $<15 \mathrm{~cm}^{3}$ and 33 subjects with $\left.>15 \mathrm{~cm}^{3}\right)(\mathbf{B})$. Each dot represents one patient. Values were compared by Mann-Whitney U-test

response with a positive AFP-specific $\mathrm{T}$ cell response was observed in most patients with advanced-stage HCC (Fig. 2D). This result highlighted the potential protective role of CTA- and SALL4-specific T cell responses in HCC patients with early-stage disease [13].

Further analyses of the correlations between the breadth of the $\mathrm{T}$ cell response, i.e., the number of CTA, SALL4 and AFP being recognized, and the tumour stage and other tumour characteristics were performed according to the distinct profile of the tumour antigenspecific $\mathrm{T}$ cell response. The association between tumour stage and the breadth of CTA- and the SALL4specific $\mathrm{T}$ cell response was analyzed, and more CTAand SALL4-specific $\mathrm{T}$ cells were detectable in patients with early-stage $\mathrm{HCC}$ than in those with advanced-stage HCC $(P=0.0104$, Fig. 3A). In addition, a comparison of the frequency of CTA-specific $\mathrm{T}$ cells between different tumour burdens showed that the breadth of recognition in patients with a low tumour burden $\left(<15 \mathrm{~cm}^{3}\right)$ was broader than that in patients with a high tumour burden $\left(>15 \mathrm{~cm}^{3}, P=0.0017\right.$, Fig. 3B).

Forty-one out of 58 HCC patients received TACE combined with RFA therapy. All 41 patients were evaluated as having complete ablation of their tumours on dynamic contrast enhancement CT scans after the operation. Among them, 17 patients did not experience recurrence of HCC during the one-year follow-up. The correlation between CTA- and SALL4-specific T cell responses and recurrence was analyzed, and a significantly stronger $\mathrm{T}$ cell response to tumour antigens was found in patients without recurrence than in those who experienced relapse $\left(177.65 \pm 61.21 \mathrm{SFUs} / 10^{6}\right.$ cells vs. $49.33 \pm 17.60 \mathrm{SFUs} / 10^{6}$ cells, $P=0.0403$, Fig. 4). Patients with early-stage HCC had $\mathrm{T}$ cells that could recognize several tumour antigens, and these specific $\mathrm{T}$ cells represent protective immunity.
The magnitude of CTA- and SALL4-specific T cell responses was stronger in patients with a low tumour burden $\left(106.72 \pm 29.03 \mathrm{SFUs} / 10^{6}\right.$ cells $)$ than in those with a high tumour burden $\left(15.45 \pm 6.26\right.$ SFUs $/ 10^{6}$ cells, $P=$ 0.0011; Fig. 5A). The frequency of recognition between the two groups was also significantly different $[68.97 \%$ (20/29) vs. $37.93 \%(11 / 29), P=0.018]$.

Moreover, SALL4- and NY-ESO-1-specific T cell responses in patients with a low tumour burden $(53.86 \pm$

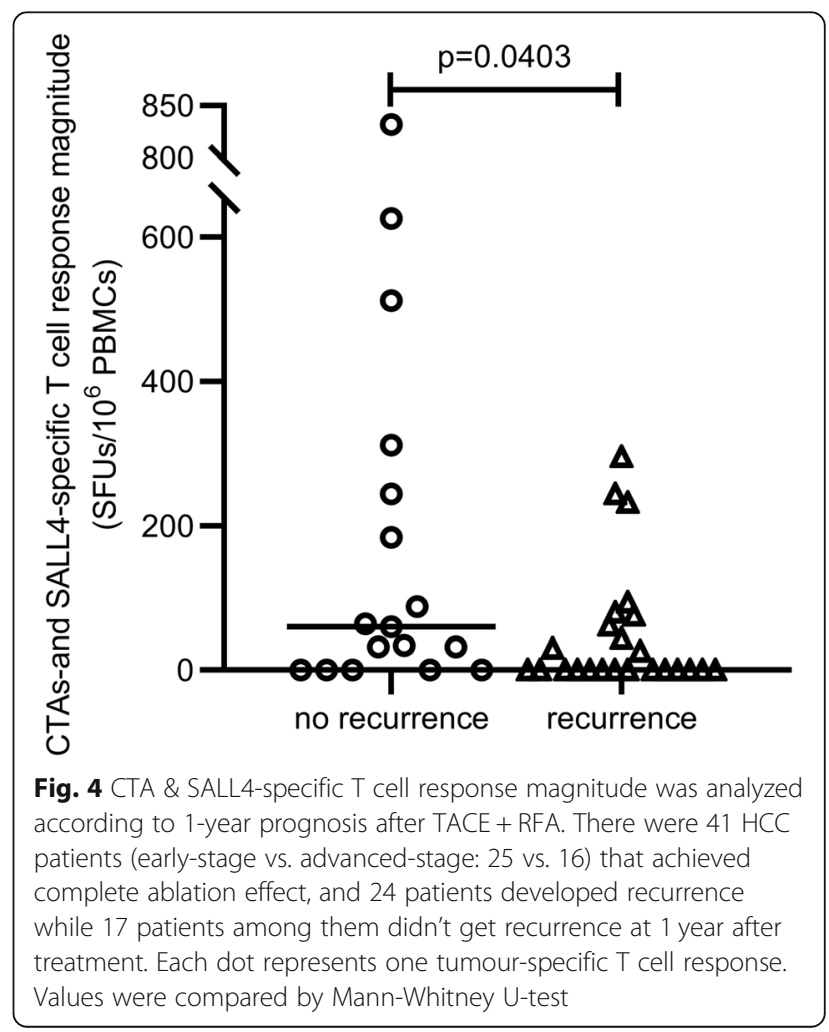




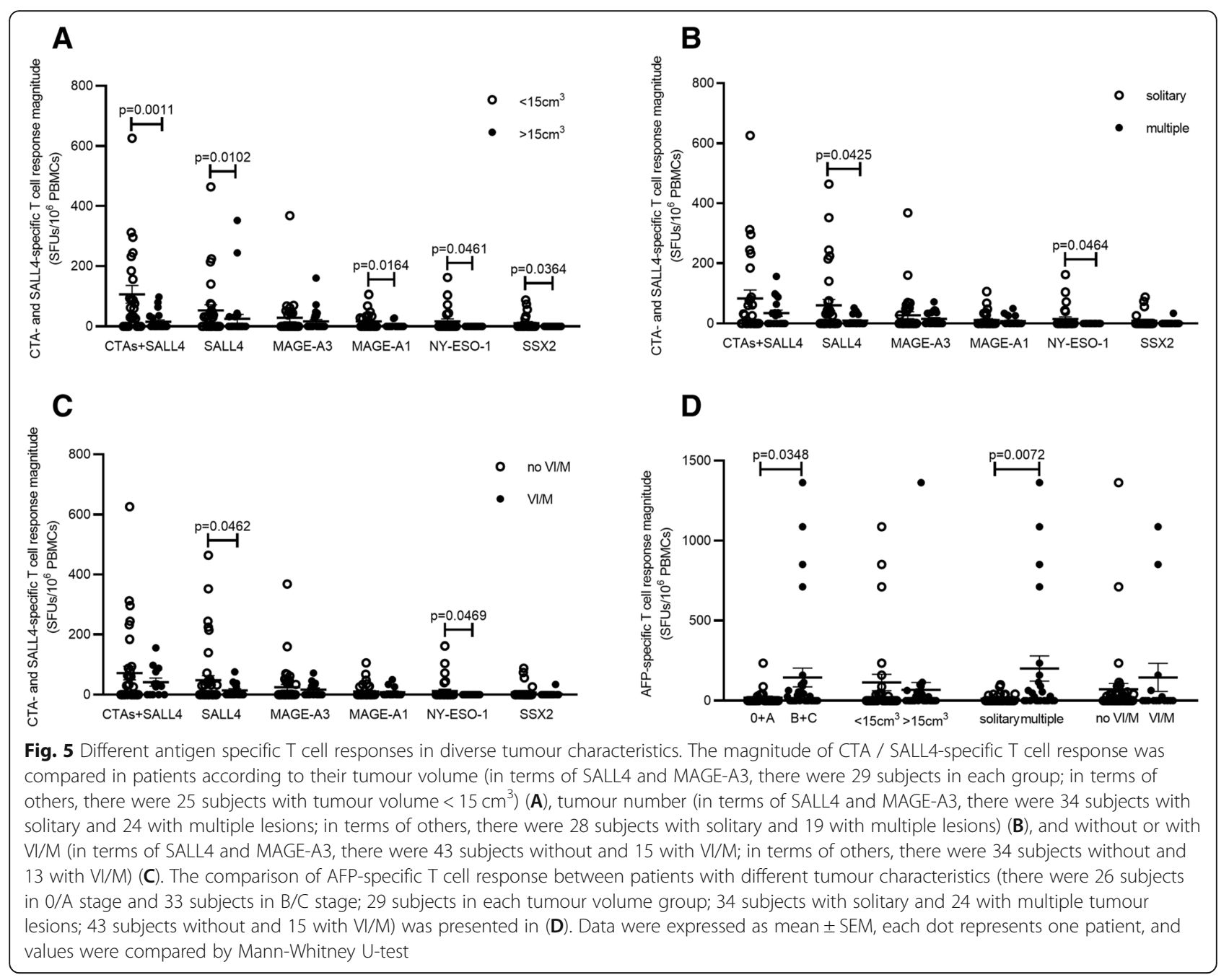

18.3 SFUs $/ 10^{6}$ cells and $16.88 \pm 8.03$ SFUs $/ 10^{6}$ cells, respectively) were significantly higher than those in patients with a high tumour burden $(25.59 \pm 14.46$ SFUs/ $10^{6}$ cells and 0 , respectively; $P=0.0102$ and $P=0.0461$, respectively; Fig. 5A). SALL4- and NY-ESO-1-specific T cell responses were significantly higher in patients with solitary lesions $\left(61 \pm 19.1\right.$ SFUs $/ 10^{6}$ cells and $15.07 \pm 7.22$ SFUs $/ 10^{6}$ cells, respectively) than in those with multiple lesions $\left(9.58 \pm 3.54\right.$ SFUs $/ 10^{6}$ cells, $P=0.0425$ and $0, P=$ 0.0464, respectively; Fig. $5 \mathrm{~B})$. These differences were also present between patients with and without vascular invasion/metastasis (VI/M) (Fig. 5C). In contrast, the AFPspecific $\mathrm{T}$ cell response showed correlations with different tumour characteristics opposite to those of the CTA/SALL4-specific T cell response. In particular, in relation to the number of tumour lesions, the AFP-specific $\mathrm{T}$ cell response was significantly stronger in patients with multiple lesions (201.75 \pm 78.65 SFUs $/ 10^{6}$ cells) than that in patients with solitary tumour lesions $\left(13.35 \pm 4.42\right.$ SFUs $/ 10^{6}$ cells, $P=0.0072$; Fig. $\left.5 \mathrm{D}\right)$. In addition, a clearly higher AFP-specific $\mathrm{T}$ cell response was found in the advanced stage $(146.18 \pm 58.75$ SFUs/ $10^{6}$ cells) compared with the early stage $(18.88 \pm 10.01$ SFUs $/ 10^{6}$ cells; $P=0.035$; Fig. $5 \mathrm{D}$ ), which indicated that the AFP-specific $\mathrm{T}$ cell response might be a signature of tumour status in the advanced stage. However, we did not find any association between the quantity of serum AFP and the magnitude of the AFP-specific $\mathrm{T}$ cell response (data not shown). The AFP-specific T cell immune response could possibly be used as a supplement to serum AFP detection. Patients whose AFP-specific T cell responses are positive or high should be followed up with closely to allow for the early detection of tumours.

Functional analysis of T cells with the progression of HCC The restriction of CTA- and TAA-specific T cell responses to $\mathrm{CD} 4+$ or $\mathrm{CD} 8+\mathrm{T}$ cells was analyzed using in vitro culture of T-cell lines stimulated by peptide pools, and the cytokine secretion and degranulation marker CD107a of the MAGE-A3-specific $\mathrm{T}$ cell line were evaluated by 


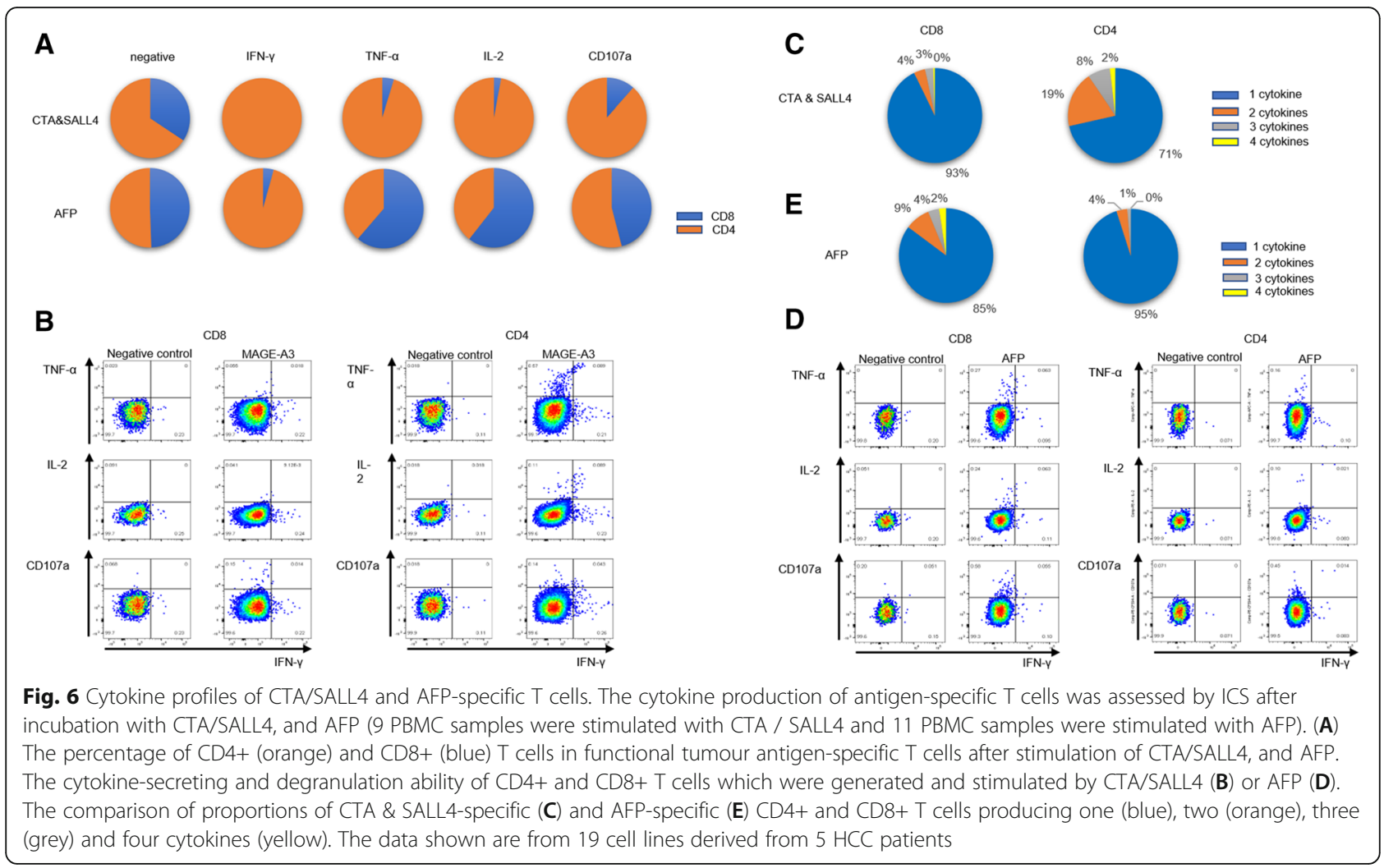

intracellular cytokine staining (ICS) with TNF- $\alpha$, IFN- $\gamma$, and IL-2. The data shown are from 19 cell lines derived from $5 \mathrm{HCC}$ patients.

A higher proportion of $\mathrm{CD} 4+\mathrm{T}$ reactive cells was observed, especially CTA/SALL4-specific responses (Fig. 6A). An example ICS is shown in Fig. 6B (The gating strategy was show in Fig. S2). Interestingly, the MAGE-A3-specific T cell population, especially the CD8+ T cell population, was dominated by cells that presented only one functional molecule evaluated (Fig. 6B/C). We also analyzed the $\mathrm{T}$ cell phenotype of patients with the AFP-specific T cell response (Fig. 6D/E) (The gating strategy was show in Fig. S3); again, AFP-specific $\mathrm{T}$ cell responses were dominated by cells producing one functional molecule evaluated in both the CD4+ and CD8+ T cell populations. Overall, we observed that CTA/SALL4-specific $\mathrm{T}$ cell responses are dominated by $\mathrm{CD} 4+$ rather than $\mathrm{CD} 8+\mathrm{T}$ cell responses, with approximately $30 \%$ of these cells presenting more than one functional molecule evaluated; in contrast, very few AFP-specific $\mathrm{CD} 4+\mathrm{T}$ cells present more than one of the functional molecules (5\%).

\section{Discussion}

In this study, we found CTA- and TAA-specific T cell responses only in patients with $\mathrm{HCC}$ and not in those with LC or CHB. Furthermore, CTA- and TAA-specific $\mathrm{T}$ cell responses were detected in $67.24 \%$ of $\mathrm{HCC}$ patients, which is higher than the rate of serum AFP positivity among patients with HCC [31]. Importantly, we found different hierarchies of CTA- and TAAspecific $\mathrm{T}$ cell responses at different stages of HCC. The SALL4-specific $\mathrm{T}$ cell response was the strongest, followed by MAGE-A3, NY-ESO-1, MAGE-A1 and SSX2, in early-stage HCC patients, whereas the AFPspecific $\mathrm{T}$ cell response was the highest in advanced HCC patients. Two opposite correlations between $\mathrm{T}$ cell response and the progression of HCC were identified. This phenomenon indicates the divergence of tumour antigens and that changes in the predominant tumour antigen-specific $\mathrm{T}$ cell response in patients with different HCC stages are common. Strong and broad CTA- \& SALL4-specific, but not AFP-specific, $\mathrm{T}$ cell responses were observed in patients with HCC that was early-stage or less aggressive. A strong relationship between the CTA- and SALL4-specific T cell response and earlystage HCC was identified, suggesting a potential protective role of this $\mathrm{T}$ cell response in the partial control of cancer development. Moreover, the association between a high CTA- and SALL4-specific T cell response and a low relapse rate of HCC at the 1-year follow-up further supports the potential protective role of the CTA- and SALL4-specific $\mathrm{T}$ cell response in early-stage HCC. Studies on SALL4 showed that the expression of SALL4 was correlated with the malignancy of $\mathrm{HCC}$ and 
suggested a poor prognosis among HCC patients [32, 33]. In this study, patients with early-stage HCC had a stronger SALL4-specific $\mathrm{T}$ cell immune response than those with advanced-stage HCC. When HCC progresses to a certain extent, tumour cells expressing SALL4 escape recognition and killing by $T$ cells, and the $T$ cell repertoire changes dramatically at different stages of HCC. Indeed, further study of the relationship between SALL4 expression and the specific $\mathrm{T}$ cell response should be performed.

These data, in line with the specific expression of CTA and SALL4 but not AFP in HCC but not normal liver, indicate the potentially important role of the CTA- and SALL4-specific $\mathrm{T}$ cell response in the early stage of $\mathrm{HCC}$ and in the control of HCC recurrence. Our study further confirmed that the expression of CTA and SALL4 in HCC tumours might promote antitumour immune surveillance and facilitate postoperative recovery [18]. Although CTA DNA is found in the late stage of HCC [34], there is a complex series of processes from gene expression to functional antigen production that can elicit an appropriate protective immune response. For example, the activity of the antigen, the immunogenicity, the expression of MHC molecule, the affinity between the MHC molecule and the antigen, and the ability of the $\mathrm{T}$ cell to recognize the antigen and to play a protection role against the antigen-expressing tumour cells. Recently, immunotherapy for HCC $[9,10]$ has not only provided more powerful evidence to support the role of immune system in controlling HCC progression but has also indicated that our understanding of $\mathrm{T}$ cell immune responses to HCC is insufficient, especially our understanding of diverse $\mathrm{T}$ cell immune statuses in different stages of HCC. Furthermore, a successfully generated MAGE-A3-specific short-term $\mathrm{T}$ cell line showed that specific cytokine-secreting $\mathrm{T}$ cells were restricted by CD4+ $\mathrm{T}$ cells, not CD8+ $\mathrm{T}$ cells. These CD8+ T cells could proliferate but remained impaired with respect to functions and were therefore undetectable by intracellular cytokine staining. Functional T cells can coexist with tumours with persisting antigens if the expression level of tumour antigens or the frequency of the $\mathrm{T}$ cells encountering tumour antigens is low [35, 36]. The study of Junliang $\mathrm{Fu}$ et al. demonstrated that $\mathrm{CD} 4+$ cytotoxic $\mathrm{T}$ cells correlated with the survival outcomes of HCC patients [37]. Additionally, further research is needed to reveal the true nature of tumour antigen-specific $\mathrm{T}$ cells.

It is known that approximately $50 \%$ of HCCs secrete AFP [38, 39], which is not only an oncofoetal antigen and diagnostic marker for liver cancer [40] but also an independent risk predictor associated with pathological grade, progression, and survival outcome [41]. In this study, the AFP-specific $\mathrm{T}$ cell response was not only found to be specific to HCC patients but was also highly distributed in patients with advanced-stage HCC, which implied that the AFP-specific $\mathrm{T}$ cell response might be a signature of tumour status in the advanced stage. The AFP-specific $\mathrm{T}$ cell response is common in patients with advanced-stage disease, which indicates the interaction between the protective role of the host $\mathrm{T}$ cell immune response to control the progression of $\mathrm{HCC}$ and the various mutations or antigenic drift from tumour cells to escape immune killing, immunoediting and immune surveillance [5, 42, 43]. ICS with a short-term $\mathrm{T}$ cell line showed that the AFP-specific $\mathrm{T}$ cell response was predominantly restricted by $\mathrm{CD} 8+\mathrm{T}$ cells, which, as responsive $\mathrm{T}$ cells, is a signature of malignant tumour status. We observed that most somatic mutations were tolerated and accumulated neutrally, confirming that mutations generating neoantigens with high immunogenicity are rare in HCC or were already immuneeliminated [42]. The cell-mediated cytotoxicity of specific $\mathrm{T}$ cells is impaired early in the cells' fate [36] in the presence of persistent antigens. Similar to intertumoral heterogeneity, the tumour-antigen-specific $\mathrm{T}$ cell response also displayed distinctions among patients, possibly due to different immunogenic stimuli or levels of immune escape. Of course, whether the function of AFP-specific T lymphocytes can be efficiently activated in vivo to target AFPexpressing tumour cells needs to be further explored.

Accordingly, we propose that tumour cells mutate and escape killing by immune cells during the progression of HCC. As tumour cells that express antigens and are recognized and killed by immune cells can be eliminated due to a lack of survival advantages, different antigen recognition spectra appear between patients with HCC in the early and advanced stages. The T-cell immune responses in earlystage HCC patients show diversity, while those with advanced-stage HCC predominantly display AFP-specific $\mathrm{T}$-cell immune responses and few other T-cells that cannot recognize tumour cells as a result of tumour evolution. Survival is achieved only by avoiding recognition and killing by immune cells. In the advanced stage of HCC, AFP-specific $\mathrm{T}$ cells become dominant and the main driving force of antitumour immunity. However, the survival ability of tumour cells at this stage has exceeded the killing ability of this antitumour immunity, and solitary AFP-specific T cells cannot control tumour progression. "While the priest climbs a post, the devil climbs ten." As the main driver of the immune response, AFP-specific $\mathrm{T}$ cells are insufficient to control and eliminate the continued growth of the malignant cells, and the ultimate result is tumour progression.

\section{Conclusions}

The results of this study indicated that the CTA- and TAA-specific $T$ cell response was only present in patients with HCC. Different hierarchies of CTA- and TAA-specific $\mathrm{T}$ cell responses were found at different stages of HCC. The SALL4-specific T cell response was 
the strongest response, followed by MAGE-A3, NYESO-1, MAGE-A1 and SSX2, in patients with earlystage HCC, whereas the AFP-specific $\mathrm{T}$ cell response was the highest in patients with advanced-stage HCC. Furthermore, strong and broad CTA- \& SALL4-specific, but not AFP-specific, $\mathrm{T}$ cell responses were observed in patients with $\mathrm{HCC}$ that was early-stage, less aggressive or with a low relapse rate at the 1-year follow-up. The application of immunotherapy in the early stage of HCC may benefit patients more.

\begin{abstract}
Abbreviations
AFP: Alpha-fetoprotein; BCLC: Barcelona Clinic Liver Cancer staging system; CHB: Chronic Hepatitis B; CTA: Cancer testis antigen; ELISPOT: Enzyme-linked immunospot assay; HC: Healthy control; HCC: Hepatocellular carcinoma; ICS: Intracellular cytokine staining; IFN-ү: Interferon-ү; IL-2: Interleukin-2; LC: Liver cirrhosis; MAGE-A1: Melanoma-associated antigen A1; NY-ESO1: New York esophageal squamous cell carcinoma antigen 1;

RFA: Radiofrequency ablation; SALL4: Sal-like gene 4; SFU: Spot-forming unit; SSX2: Synovial sarcoma X break point gene 2; TAA: Tumor-associatedantigen; TACE: Transcatheter arterial chemoembolization; TNF-a: Tumor necrosis factor $\mathrm{a}$; VI/M: Vascular invasion/metastasis
\end{abstract}

\section{Supplementary Information}

The online version contains supplementary material available at https://doi. org/10.1186/s12885-021-08720-9.

Additional file 1: Table S1. The sequences of the overlapping peptides for each of the six antigens and their position within the protein sequence.

Additional file 2: Fig. S1. The example picture of the tumour antigenspecific T cell response results in HC, CHB, LC controls and HCC.

Additional file 3: Fig. S2. Gating strategy of cytokines on CD4 and CD8 T cells in MAGE-A3-stimulated short-term T cell lines. Progressive gating strategy was used to exclude doublets and dead cells and to identify CD4 and CD8 T cells afterwards. Unstimulated controls were applied accordingly in order to properly position gates of cytokines. The abscissa axis of the final gating strategy graphs was IFN- $\gamma$, and the vertical axis of the three gating strategy graphs of CD8+ T cells was TNF-a, $I L-2$, and CD107a from top to bottom, of CD4+ T cells was TNF-a, IL-2, and CD107a from left to right.

Additional file 4: Fig. S3. Gating strategy of cytokines on CD4 and CD8 $\mathrm{T}$ cells in AFP-stimulated short-term T cell lines. Progressive gating strategy was used to exclude doublets and dead cells and to identify CD4 and CD8 T cells afterwards. Unstimulated controls were applied accordingly in order to properly position gates of cytokines. The abscissa axis of the final gating strategy graphs was IFN- $\gamma$, and the vertical axis of the three gating strategy graphs of CD8+ T cells was TNF- $a, \mathrm{IL}-2$, and CD107a from top to bottom, of CD4+ T cells was TNF-a, IL-2, and CD107a from left to right.

\section{Acknowledgements}

Not applicable.

\section{Authors' contributions}

$Y H Z, Y Z$ and T D conceptualized and designed the study. CR Z, Y Z and YH $Z$ analyzed the data. CR Z, L Q, GH L, JP S, K L, YN Z, SP S, HH Z, N H, P Z, and $Q$ W helped with the clinical sample and data collection, $X L$ and $Y C P$ provided critical reagents, $C R Z$ and $Y H Z$ wrote the manuscript, $Y H Z$, T D and $K L$ reviewed and revised the manuscript. The author(s) read and approved the final manuscript.

\section{Funding}

This work was supported by the Beijing Natural Science Foundation (7191004 and 7202069), Beijing Municipal Science \& Technology Commission
(Z171100001017078), Capital health development project (2020-1-2182 and 2020-2-1153), Beijing municipal administration of hospitals (DFL20181701 and ZYLX201711), Beijing Key Laboratory (BZ0373), and Chinese Academy of Medical Sciences (CAMS) Innovation Fund for Medical Sciences (CIFMS), China (grant number: 2018-I2M-2-002).

\section{Availability of data and materials}

The raw data of this study are derived from our hospital. All detailed data included in the study are available upon request by contact with the corresponding author.

\section{Declarations}

Ethics approval and consent to participate

This study was approved the Ethic Committee of Beijing YouAn Hospital (approved number: [2019] No.023), and the study was conducted in compliance with the principle of the Declaration of Helsinki. Written informed consent was obtained from all patients or their family members.

\section{Consent for publication}

Not applicable.

\section{Competing interests}

The authors declare that they have no competing interests.

\section{Author details}

${ }^{1}$ Biomedical Information Center, Beijing YouAn Hospital, Capital Medical University, Beijing, China. ${ }^{2}$ Interventional Therapy Center of Liver Disease, Beijing YouAn Hospital, Capital Medical University, Beijing, China. ${ }^{3}$ Clinical Laboratory Center, Beijing YouAn Hospital, Capital Medical University, Beijing, China. ${ }^{4}$ MRC Human Immunology Unit, MRC Weatherall Institute of Molecular Medicine, Oxford University, Oxford, UK. ${ }^{5}$ CAMS Oxford Institute, Nuffield Department of Medicine, Oxford University, Oxford, UK. 'Department of Radiology and Research Institute of Radiology, The Affiliated Cancer Hospital of Zhengzhou University, Henan Cancer Hospital, Zhengzhou, Henan, China.

Received: 25 April 2021 Accepted: 19 August 2021

Published online: 08 September 2021

\section{References}

1. Villanueva A. Hepatocellular Carcinoma. N Engl J Med. 2019;380(15):1450-62. https://doi.org/10.1056/NEJMra1713263.

2. Zheng R, Qu C, Zhang S, Zeng H, Sun K, Gu X, et al. Liver cancer incidence and mortality in China: temporal trends and projections to 2030. Chin J Cancer Res. 2018;30(6):571-9. https://doi.org/10.21147/j.issn.1000-9604.2018. 06.01.

3. Blair GE, Cook GP. Cancer and the immune system: an overview. Oncogene. 2008:27(45):5868. https://doi.org/10.1038/onc.2008.277.

4. Kaufmann SH. Immunology's foundation: the 100-year anniversary of the Nobel prize to Paul Ehrlich and Elie Metchnikoff. Nat Immunol. 2008;9(7): 705-12. https://doi.org/10.1038/ni0708-705.

5. Hanahan D, Weinberg RA. Hallmarks of cancer: the next generation. Cell. 2011;144(5):646-74. https://doi.org/10.1016/j.cell.2011.02.013.

6. Foerster F, Hess M, Gerhold-Ay A, Marquardt J, Becker D, Galle P, et al. The immune contexture of hepatocellular carcinoma predicts clinical outcome. Sci Rep. 2018;8(1):5351. https://doi.org/10.1038/s41598-018-21937-2.

7. Gabrielson A, Wu Y, Wang H, Jiang J, Kallakury B, Gatalica Z, et al. Intratumoral CD3 and CD8 T-cell densities associated with relapse-free survival in HCC. Cancer Immunol Res. 2016;4(5):419-30. https://doi.org/10.11 58/2326-6066.CIR-15-0110.

8. Hiroishi K, Equchi J, Baba T, Shimazaki T, Ishii S, Hiraide A, et al. Strong CD8(+) T-cell responses against tumor-associated antigens prolong the recurrence-free interval after tumor treatment in patients with hepatocellular carcinoma. J Gastroenterol. 2010;45(4):451-8. https://doi.org/1 0.1007/s00535-009-0155-2.

9. El-Khoueiry AB, Sangro B, Yau T, Crocenzi TS, Masatoshi K, Chiun H, et al. Nivolumab in patients with advanced hepatocellular carcinoma (CheckMate 040): an open-label, non-comparative, phase 1/2 dose escalation and expansion trial. Lancet. 2017;389:2492-502. 
10. Xu J, Zhang Y, Jia R, Yue C, Chang L, Liu R, et al. Anti-PD-1 antibody SHR1210 combined with Apatinib for advanced hepatocellular carcinoma, gastric, or Esophagogastric junction Cancer: an open-label, dose escalation and expansion study. Clin Cancer Res. 2019;25(2):515-23. https://doi.org/1 0.1158/1078-0432.CCR-18-2484.

11. Sarobe P, Feijoó E, Alfaro C, Mazzolini G, Melero I. MAGE antigens: therapeutic targets in hepatocellular carcinoma? J Hepatol. 2004;40(1):155-8. https://doi.org/10.1016/j.jhep.2003.10.013.

12. Tauber C, Schultheiss M, Luca R, Buettner N, Liewellyn-Lacey S, Emmerich F, et al. Inefficient induction of circulating TAA-specific CD8+ T-cell responses in hepatocellular carcinoma. Oncotarget. 2019;10(50):5194-206. https://doi. org/10.18632/oncotarget.27146.

13. Abd Hamid M, Peng YC, Dong T. Human cancer germline antigen-specific cytotoxic T cell-what can we learn from patient. Cell Mol Immunol. 2020; 17(7):684-92. https://doi.org/10.1038/s41423-020-0468-x.

14. Smith CC, Selitsky SR, Chai S, Armistead PM, Vincent BG, Serody JS. Alternative tumor-specific antigens. Nat Rev Cancer. 2019;19(8):465-78. https://doi.org/10.1038/s41568-019-0162-4.

15. Masuda S, Suzuki K, Izpisua Belmonte JC. Oncofetal gene SALL4 in aggressive hepatocellular carcinoma. N Engl J Med. 2013;368:2266-76.

16. Wang X, Wang Q. Alpha-fetoprotein and hepatocellular carcinoma immunity. Can J Gastroenterol Hepatol. 2018;2018:9049252.

17. Nicholaou T, Ebert L, Davis ID, Robson N, Klein O, Maraskosky E, et al. Directions in the immune targeting of cancer: lessons learned from the cancer-testis ag NY-ESO-1. Immunol Cell Biol. 2006;84(3):303-17. https://doi. org/10.1111/j.1440-1711.2006.01446.X.

18. Liang J, Ding T, Guo ZW, Yu X, Hu Y, Zheng L. Expression pattern of tumorassociated antigens in hepatocellular carcinoma: association with immune infiltration and disease progression. Br J Cancer. 2013;109(4):1031-9. https:// doi.org/10.1038/bjc.2013.390

19. Heimbach JK, Kulik LM, Finn RS, Sirlin CB, Abecassis MM, Roberts LR, et al. AASLD guidelines for the treatment of hepatocellular carcinoma. Hepatology. 2018;67(1):358-80. https://doi.org/10.1002/hep.29086.

20. Tellapuri S, Sutphin PD, Beg MS, Singal AG, Kalva SP. Staging systems of hepatocellular carcinoma: a review. Indian J Gastroenterol. 2018;37(6):48191. https://doi.org/10.1007/s12664-018-0915-0.

21. Xu ZT, Xie HY, Zhou L, Chen XH, Zheng SS. The Combination Strategy of Transarterial Chemoembolization and Radiofrequency Ablation or Microwave Ablation against Hepatocellular Carcinoma. Anal Cell Pathol. 2019;2019(8619096).

22. Jiang C, Cheng G, Liao MH, Huang JW. Individual or combined transcatheter arterial chemoembolization and radiofrequency ablation for hepatocellular carcinoma: a time-to-event meta-analysis. World J Surg Oncol. 2021;19(1):81. https://doi.org/10.1186/s12957-021-02188-4

23. Li W, Wang Y, Gao WF, Zheng JS. Combination of transcatheter arterial chemoembolization and CT-guided percutaneous segment ablation for hepatocellular carcinoma therapy. Medicine. 2016;95:e5422.

24. Wang Y, Ma L, Sheng SP, Yuan ZH, Zheng JS, Li W. Combination therapy of TACE and CT-guided partial hepatic segment ablation for liver cancer. Minim Invasive Ther Allied Technol. 2018;27(6):355-64. https://doi.org/10.1 080/13645706.2018.1462833.

25. Wang Y, Ma L, Yuan ZH, Zhang JS, Li W. Percutaneous thermal ablation combined with TACE versus TACE monotherapy in the treatment for liver cancer with hepatic vein tumor thrombus: a retrospective study. PLoS One. 2018;13(7):e0201525. https://doi.org/10.1371/journal.pone.0201525.

26. Long J, Wang HG, Zhao P, Sheng SP, Shi QS, Long M, et al. Transarterial chemoembolization combined with radiofrequency ablation for solitary large hepatocellular carcinoma ranging from 5 to $7 \mathrm{~cm}$ : an 8-year prospective study. Abdom Radiol. 2020;45:2736-47.

27. Chen K, Zhan MX, Hu BS, Li Y, He X, Fu SR, et al. Combination of the neutrophil to lymphocyte ratio and the platelet to lymphocyte ratio as a useful predictor for recurrence following radiofrequency ablation of hepatocellular carcinoma. Oncol Lett. 2018;15(1):315-23. https://doi.org/10.3 892/ol.2017.7291.

28. Fukui H, Saito H, Ueno Y, Uto H, Obara K, Sakaida I, et al. Evidence-based clinical practice guidelines for liver cirrhosis 2015. J Gastroenterol. 2016; 51(7):629-50. https://doi.org/10.1007/s00535-016-1216-y.

29. Terrault NA, Lok ASF, McMahon BJ, Chang KM, Hwang JP, Jonas MM, et al. Update on prevention, diagnosis, and treatment of chronic hepatitis $B$ : AASLD 2018 hepatitis B guidance. Hepatology. 2018;67(4):1560-99. https:// doi.org/10.1002/hep.29800.
30. Zhang YH, Peng YC, Yan HP, Xu KY, Saito M, Wu H, et al. Multilayered defense in HLA-B51-associated HIV viral control. J Immunol. 2011;187(2): 684-91. https://doi.org/10.4049/jimmunol.1100316.

31. Chen DS, Sung JL, Sheu JC, Lai MY, How SW, Hsu HC, et al. Serum alphafetoprotein in the early stage of human hepatocellular carcinoma. Gastroenterology. 1984;86(6):1404-9. https://doi.org/10.1016/S0016-5085(84 )80151-1.

32. Yin F, Han X, Yao SK, Wang XL, Yang HC. Importance of SALL4 in the development and prognosis of hepatocellular carcinoma. World J Gastroenterol. 2016;22(9):2837-43. https://doi.org/10.3748/wjg.v22.i9.2837.

33. Wang HL, Kohashi K, Yoshizumi T, Okumura Y, Tanaka Y, Shimokawa M, et al. Co-expression of SALL4 with HDAC1 and/or HDAC2 is associated with underexpression of PTEN and poor prognosis in patients with hepatocellular carcinoma. Hum Pathol. 2017;64:69-75. https://doi.org/10.101 6/j.humpath.2017.03.007.

34. Zhao L, Mou DC, Peng JR, Huang L, Wu ZA, Li XS. Diagnostic value of cancer-testis antigen mRNA in peripheral blood from hepatocellular carcinoma patients. World J Gastroenterol. 2010;16(32):4072-8. https://doi. org/10.3748/wjg.v16.i32.4072.

35. Wherry EJ. T cell exhaustion. Nat Immunol. 2011;12(6):492-9. https://doi. org/10.1038/ni.2035.

36. Wherry EJ, Blattman JN, Murali-Krishna K, van der Most R, Ahmed R. Viral persistence alters CD8 T-cell immunodominance and tissue distribution and results in distinct stages of functional impairment. J Virol. 2003;77(8):491127. https://doi.org/10.1128/JVI.77.8.4911-4927.2003.

37. Fu JL, Zhang Z, Zhou L, Qi ZR, Xing SJ, Lv JY, et al. Impairment of CD4+ cytotoxic $T$ cells predicts poor survival and high recurrence rates in patients with hepatocellular carcinoma. Hepatology. 2013;58(1):139-49. https://doi. org/10.1002/hep.26054.

38. Forner A, Llovet JM, Bruix J. Hepatocellular carcinoma. Lancet. 2012; 379(9822):1245-55. https://doi.org/10.1016/S0140-6736(11)61347-0.

39. Song PP, Xia JF, Inagaki Y, Hasegawa K, Sakamoto Y, Kokudo N, et al. Controversies regarding and perspectives on clinical utility of biomarkers in hepatocellular carcinoma. World J Gastroenterol. 2016;22(1):262-74. https:// doi.org/10.3748/wjg.v22.i1.262.

40. Zheng YF, Zhu MY, Li MS. Effects of alpha-fetoprotein on the occurrence and progression of hepatocellular carcinoma. J Cancer Res Clin Oncol. 2020; 146(10):2439-46. https://doi.org/10.1007/s00432-020-03331-6.

41. Bai DS, Zhang C, Chen P, Jin SJ, Jiang GQ. The prognostic correlation of AFP level at diagnosis with pathological grade, progression, and survival of patients with hepatocellular carcinoma. Sci Rep. 2017;7(1):12870. https://doi. org/10.1038/s41598-017-12834-1.

42. Dong LQ, Peng LH, Ma L, Liu DB, Zhang S, Luo SZ, et al. Heterogeneous immunogenomic features and distinct escape mechanisms in multifocal hepatocellular carcinoma. J Hepatol. 2020;72(5):896-908. https://doi.org/10.1 016/j.j.hep.2019.12.014.

43. Kristensen VN. The antigenicity of the tumor cell - context matters. N Engl J Med. 2017;376(5):491-3. https://doi.org/10.1056/NEJMcibr1613793.

\section{Publisher's Note}

Springer Nature remains neutral with regard to jurisdictional claims in published maps and institutional affiliations.

Ready to submit your research? Choose BMC and benefit from:

- fast, convenient online submission

- thorough peer review by experienced researchers in your field

- rapid publication on acceptance

- support for research data, including large and complex data types

- gold Open Access which fosters wider collaboration and increased citations

- maximum visibility for your research: over $100 \mathrm{M}$ website views per year

At BMC, research is always in progress.

Learn more biomedcentral.com/submissions 